\title{
Preventative Medicine as a Service in Tourism - Health Awareness
}

\author{
Jens Thonack ${ }^{1 *}$ and Martin Hofmann ${ }^{2}$
}

${ }^{1}$ General Medical Practitioner, Dostojewskistrasse 3a, 17491 Greifswald, Germany

${ }^{2}$ Wellness Department Director, Hotel zur Post, Seestrasse 5, 17429 Seeheilbad Bansin, Germany

\begin{abstract}
Background: The scope of this project was the implementation of technology from vitalexpertise $₫$ as a quality system for guest support in tourism. An organisation model based on the conceptual and structural requirements was developed.

Methods: The surveying of the guests was carried out within the framework of the German Federal Ministry for Education and Research project called "Development of a Quality Assurance System in a Preventative Self-pay Market." Questionnaires were handed-out both at guests' arrival and departure. Twenty-three people were surveyed.

Results: The results should be considered in the social context and individual situations of each guest. Guests showed curative knowledge, but only slightly so in the area of preventative medicine in the sense of salutogenesis. The self-assessment of the guests on the topic of health-consciousness does not correlate with the actual activities in daily living.

Conclusion: A guest's rethinking of salutogenesis principles is not shown. The spread of knowledge aimed at health preservation activities must be achieved. Because of the recovery time, duration of stay, calmness etc. in a hotel, the prerequisites for spreading of salutogenesis principles exists. While the acceptance of such offerings in hotels are noticeable, theoretic knowledge and implementation in everyday living is not.
\end{abstract}

Keywords: Health intelligence; Health promotion; Health services

\section{Introduction}

In this pilot study, the acceptance of the practice of preventative medicine (for example vitalexpertise ${ }^{\oplus}[1,2]$ and preventative aspects in daily-life by guests in a wellness hotel) was examined. The surveying of guests was accomplished within the framework of the Bundesministerium für Bildung und Forschung [Federal Ministry for Education and Research] project, "Development of a quality assurance system in a preventative self-pay patient market".

In this pilot project, the acceptance of medical prevention offers in a hotel is investigated. Whether or not medical services in vacation destinations will be adopted by guests should be investigated.

\section{Background}

As declared politically [3], prevention shall play a bigger roll in medical supply. Because of demographic changes, it becomes ever more important that people concern themselves with preventative medicine, or rather, the prevention of diseases. With that, they should acquire and then implement knowledge gained on this topic. In the past, primary medical care dealt solely with prevention in the areas of immunization and cancer care. However, they failed in the areas of primary preventative measures for diseases of today's civilisation such as obesity, diabetes mellitus, circulatory disorders, etc. Diseases of today's civilisation are steadily increasing. In order for people to start practicing prevention and to test the practicality, a project was conducted with the goal of establishing preventative medicine practices in tourism.

The future will show the extent of the preventative benefits and their capacity. The tourism industry has already realised the significance of preventative medicine in a hotel [4]. The health insurance companies support tourism in this respect. Like every provider, the hotel must provide a certified course instructor and observe the general conditions. If the criteria of SGB V $\$ 20$ (Social Act V par. 20) are met, the insurance companies will give their financial support [5].

\section{Methods}

For the methodical execution, basic conditions were given. The survey was in conducted in a hotel. This study was carried out in an authentic and practical way, so that neither logistical nor structural changes within the hotel took place. Only the personnel at the reception desk and in the wellness department were trained to conduct the survey.

This study did not require approval from an ethics committee. The surveying of guests, comprising the analysis via vitalexpertise ${ }^{\curvearrowleft}$, did not include ethical aspects.

Upon guests' arrival and check-in at the reception desk, they were informed of the offer to authorise the conducting of the vitalexpertise analysis. At this informing, guests were shown vitalexpertise ${ }^{\circledR}$ as a preventative analysis and, therein, useful as a lifestyle corrector. At consent, an appointment for the undergoing of the analysis was arranged.

At departure, another survey followed.

The questionnaire was designed so that one could grasp the everyday situations, health awareness and resonance of the offers. The questionnaire should be kept short, so that the guest does not get the impression of being in a health treatment facility.

The questionnaire was constructed using the experiences of doctors, wellness experts and hotel experts. A test of the validity did

*Corresponding author: Jens Thonack, General Medical Practitioner, Dostojewskistrasse 3a, 17491 Greifswald, Germany, E-mail: thonack@uni-greifswald.de

Received May 07, 2012; Accepted May 28, 2012; Published May 30, 2012

Citation: Thonack J, Hofmann M (2012) Preventative Medicine as a Service in Tourism - Health Awareness. Primary Health Care 2:116. doi:10.4172/2167 1079.1000116

Copyright: ( $) 2012$ Thonack J, et al. This is an open-access article distributed under the terms of the Creative Commons Attribution License, which permits unrestricted use, distribution, and reproduction in any medium, provided the original author and source are credited. 
Citation: Thonack J, Hofmann M (2012) Preventative Medicine as a Service in Tourism - Health Awareness. Primary Health Care 2:116. doi:10.4172/2167-1079.1000116

Page 2 of 6

not occur because of the short project duration. A short pre-test was conducted.

Twenty-three guests (11 men and 12 women) were questioned. The average age was 50.8 years (women: 51.5 years; men: 50.0 years). The questionnaire was distributed at arrival and departure.

The evaluation of the results of five test persons was made through a personal interview with a doctor and the other guests were questioned by employees of the wellness area of the hotel. Every guest received a written evaluation with recommendations.

During the interviews using the questionnaire, individual questions were answered, and recommendations for the stay in the hotel were given.
Because of the small test group, the evaluation of the results occurred without a computer-supported statistical program. The evaluation results were accomplished manually (Tables 1 and 2).

\section{Results}

The results show a discrepancy between theoretical assessment and practical daily living.

In figures 1-3 you can see that over 50\% of the participants show high health awareness without identifying a practical implementation in daily life. What was actually implemented in daily life is shown in figures 2-5. The results reflect not only the practical implementation but importantly provide advanced information on the single areas of the guests' lives in order to provide optimal support in the hotel.

\begin{tabular}{|c|c|c|c|}
\hline $\begin{array}{l}\text { Does prevention play a role in your daily } \\
\text { life? }\end{array}$ & Large & Small & Not specified \\
\hline $\begin{array}{l}\text { How would you assess your health } \\
\text { awareness? }\end{array}$ & High & Low & Not specified \\
\hline $\begin{array}{l}\text { How did you become aware of vitalex- } \\
\text { pertise } ® \text { ? }\end{array}$ & Hotel information & Internet & Another media \\
\hline $\begin{array}{l}\text { Why have you decided on preventative } \\
\text { medical measures? }\end{array}$ & To stay vital & Physical examinations other than by GP & $\begin{array}{l}\text { Individual analysis of many factors of my } \\
\text { health }\end{array}$ \\
\hline $\begin{array}{l}\text { How would you evaluate the work of your } \\
\text { general practitioner? }\end{array}$ & Predominantly to treat illnesses. & Predominantly to maintain good health. & No conclusion \\
\hline $\begin{array}{l}\text { In the last } 12 \text { months, how often have } \\
\text { you undergone a preventative medical } \\
\text { examination or other preventative medi- } \\
\text { cal measure? }\end{array}$ & 1-2 times & 3-5 times & None \\
\hline Walking & Daily & 2-3 times per week & More than 4 times per week \\
\hline \multicolumn{4}{|l|}{$<1$ hour } \\
\hline \multicolumn{4}{|l|}{$>1$ hour } \\
\hline Do you exercise? & Yes & No & \\
\hline \multicolumn{4}{|l|}{ Yes = Which exercises $?$} \\
\hline & Daily & 2-3 times per week & More than 4 times per week \\
\hline \multicolumn{4}{|l|}{$<1$ hour } \\
\hline \multicolumn{4}{|l|}{$>1$ hour } \\
\hline Do you exercise? & Yes & No & \\
\hline \multicolumn{4}{|l|}{ Yes $=$ Which exercise $?$} \\
\hline & Daily & 2-3 times per week & More than 4 times per week \\
\hline \multicolumn{4}{|l|}{$<1$ hour } \\
\hline \multicolumn{4}{|l|}{$>1$ hour } \\
\hline \multicolumn{4}{|l|}{ Which illnesses do you have? } \\
\hline \multicolumn{4}{|c|}{ 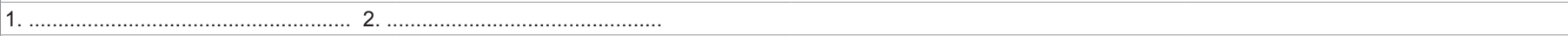 } \\
\hline \multicolumn{4}{|c|}{ 3. } \\
\hline \multicolumn{4}{|c|}{ 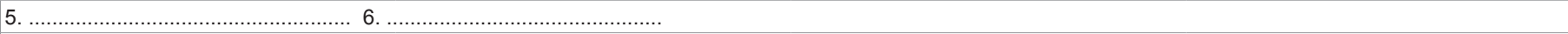 } \\
\hline \multicolumn{4}{|c|}{ 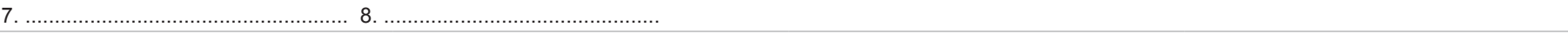 } \\
\hline \multicolumn{4}{|c|}{ Which aspects of your food/nutrition do you pay attention to? } \\
\hline & Yes & No & No aspect \\
\hline \multicolumn{4}{|l|}{ "l'll eat anything served to me" } \\
\hline \multicolumn{4}{|l|}{ Varied diet } \\
\hline \multicolumn{4}{|l|}{ Vegetarian } \\
\hline \multicolumn{4}{|l|}{ Reduced-fat } \\
\hline \multicolumn{4}{|l|}{ > 2I Liquids } \\
\hline \multicolumn{4}{|l|}{3 servings of vegetables daily } \\
\hline \multicolumn{4}{|l|}{2 servings of fruit daily } \\
\hline \multicolumn{4}{|l|}{ Low-salt } \\
\hline \multicolumn{4}{|l|}{ Low-cholesterol } \\
\hline \multicolumn{4}{|l|}{ Low-sugar } \\
\hline \multicolumn{4}{|l|}{ Protein-rich } \\
\hline \multicolumn{4}{|l|}{ Alcohol: } \\
\hline & Daily & 2-3 times per week & More than 4 times per week \\
\hline \multicolumn{4}{|l|}{ Beer } \\
\hline Wine & & & \\
\hline
\end{tabular}


Citation: Thonack J, Hofmann M (2012) Preventative Medicine as a Service in Tourism - Health Awareness. Primary Health Care 2:116. doi:10.4172/2167-1079.1000116

Page 3 of 6

\begin{tabular}{|c|c|c|c|}
\hline \multicolumn{4}{|l|}{ Schnapps } \\
\hline \multicolumn{4}{|c|}{\begin{tabular}{l|l} 
Cocktails & \\
\end{tabular}} \\
\hline \multicolumn{4}{|c|}{ Do you take multi-vitamins / vital substances? } \\
\hline & Yes & No & \\
\hline \multicolumn{4}{|l|}{ If so, when? } \\
\hline & Daily & 2-3 times per week & More than 4 times per week \\
\hline \multicolumn{4}{|l|}{ Multi-vitamin } \\
\hline \multicolumn{4}{|c|}{ Please give individual supplements / active ingredients! } \\
\hline & Daily & 2-3 times per week & More than 4 times per week \\
\hline \multicolumn{4}{|r|}{ ( } \\
\hline \multicolumn{4}{|l|}{2.} \\
\hline \multicolumn{4}{|l|}{3.} \\
\hline \multicolumn{4}{|l|}{4.} \\
\hline \multicolumn{4}{|l|}{5.} \\
\hline \multicolumn{4}{|c|}{ How tall are you? } \\
\hline \multicolumn{4}{|c|}{ How much do you weight? } \\
\hline \multicolumn{4}{|c|}{ Is your daily life very stressful? } \\
\hline \multicolumn{4}{|c|}{ Do you feel stress from your daily work life? } \\
\hline & Yes & No & \\
\hline \multicolumn{4}{|l|}{ Do you smoke? } \\
\hline \multicolumn{4}{|c|}{ One cigarette per month is still smoking! } \\
\hline & Yes & No & \\
\hline Are you pregnant? & & & \\
\hline
\end{tabular}

Table 1: Questionnaire at Check-in.

\section{Question}

Were your expectations met during your stay?

Was the service optimal?

Was the service personnel friendly?

Was the unique selling point of the MEDICAL SPA clearly found in all departments in Hotel zur Post?

Was vitalexpertise $®$ a benefit for you?

Have you learned new information about health during your stay?

Did your illnesses or psychological problems improve during your stay at Hotel zur Post?

Was the evaluation of vitalexpertise ${ }^{\circledR}$ on the monitor convenient?

Would you consider another stay in this hotel?

Please make an " $X$ " in each box.

$1=$ excellent $2=$ very good $3=$ good $4=$ satisfactory $5=$ inadequate $6=$ poor

Table 2: Questionnaire at Check-out.

On the other hand, the self-assessment of the guests showed that those who chose preventative measures had, in their own point of view, high health awareness (Figure 2).

Likewise the participation in a preventive examination was high.

More background information about individual areas of the guests' lives was essential for the assistance during their hotel stay. For the guest to be optimally advised, guests were asked about previous knowledge in the areas of nutrition, exercise and stress. Figures 4-6 show the results in each area.

The question of which types of exercise are conducted should form the basis for a specific consultation. During the intervention, the extent, intensity and efficiency of the type of exercise should be considered (Figure 7).

A further question focused on the reason for that decision. Here, three different answers were given. In figure 8 it is clearly shown that the individual statement and the preservation of health stand in the foreground. One must keep in mind that in Germany, medical prevention does not have a large social roll. In medicine as well, prevention plays and inferior roll.
At the end of the stay in the hotel, the guest was surveyed again. The goal was to obtain answers about the overall impression of the hotel stay, and especially answers to the question of the knowledge acquired pertaining to the subject of prevention and healthcare. It was shown that a large part of the guests were very satisfied (Figure 9).

There was a greater inconsistency about knowledge gained to the subject of prevention and health care. However, the majority of the guests answered that they did gain knowledge during their stay (Figure 10). On vacation one has time to deal more intensely with these topics. The knowledge gained as a theoretical basis is regarded very positively. The decision is whether or not the acquired knowledge will be implemented at home.

A universal question, which inquired if the guest considered repeating the stay, was answered positively.

From these results, one can see in figure 10 that the preventative medicine measure (for example, vitalexpertise ${ }^{\infty}$ ) including the consultation of the guest was an added value.

\section{Discussion}

The goal of attracting more people to preventative medicine meets 


\section{Role of prevention in everyday life}

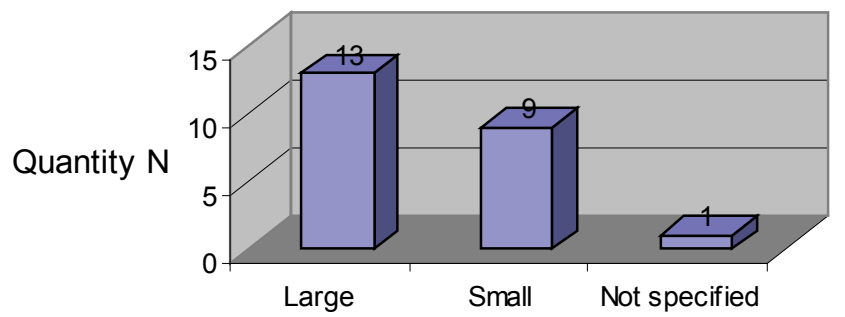

Figure 1: Does medical prevention play a role in your daily life?

\section{Self-assessment of health awareness}

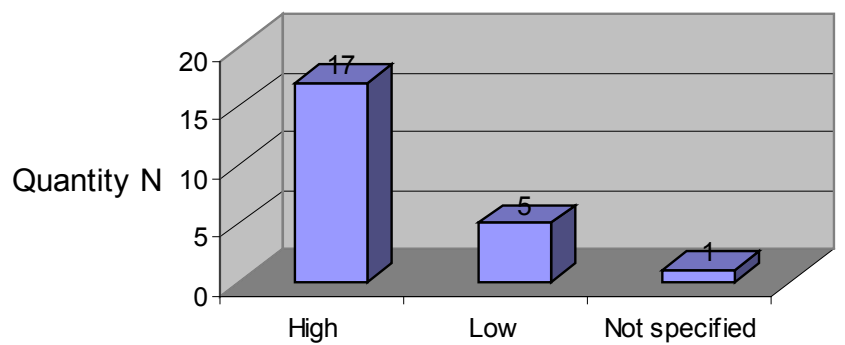

Figure 2: How would you assess your health awareness?

Number of completed preventative medical examinations or other preventative medical measures in the last 12 months

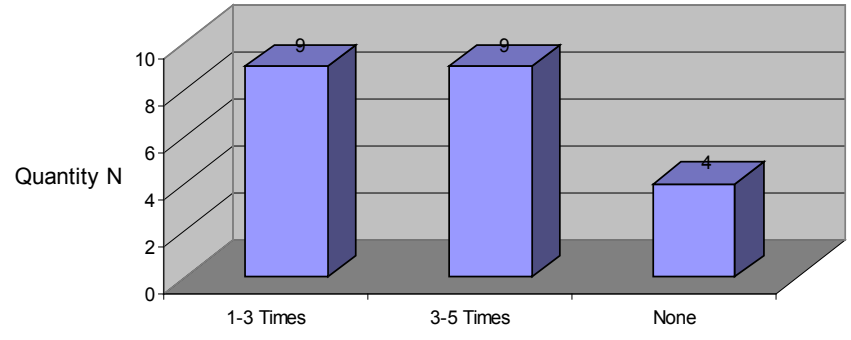

Figure 3: In the last 12 months, how often have you undergone a preventative medical examination or other preventative medical measure?

the requirements of this procedure. However, one should not overlook the risks. The guest could be a patient with chronic diseases. He could then be recommended to the individual courses where undesired reactions could occur to the guest. This is a minor risk; still every hotel offering preventative medicine courses should cooperate with a local doctor for these cases.

From figures 1 and 2 we learn that the guests have various definitions for prevention and health awareness. In the mentality of the German population, the focus lies on curative medicine. The mentality of preventative medicine is still rather under-represented. The results show that guests with a high priority of preservation of their health have decided on preventative medicine measures for themselves. For this reason the questions about healthcare in the last 12 months were necessary (Figure 3 ). The results confirm that the guests occupy themselves with their healthcare.

Figures 4 through 6 show an inconsistency about the knowledge of

\section{Do you exercise?}

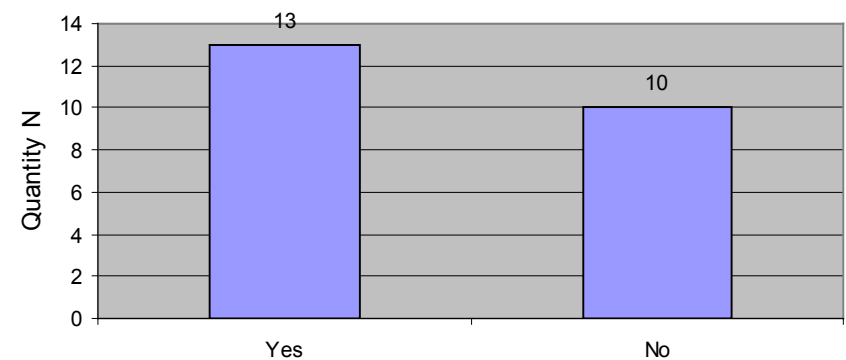

Figure 4: Do you exercise?

\section{Stressful daily life?}

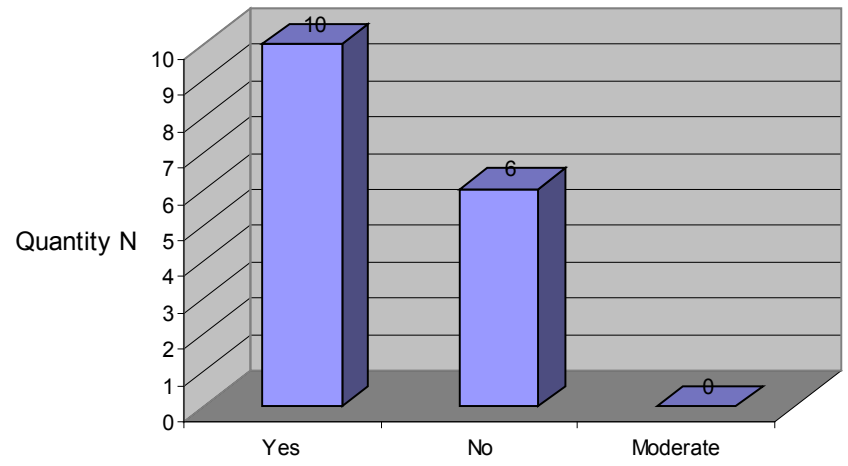

Figure 5: Is your workday stressful?

\section{Assessment of diet}

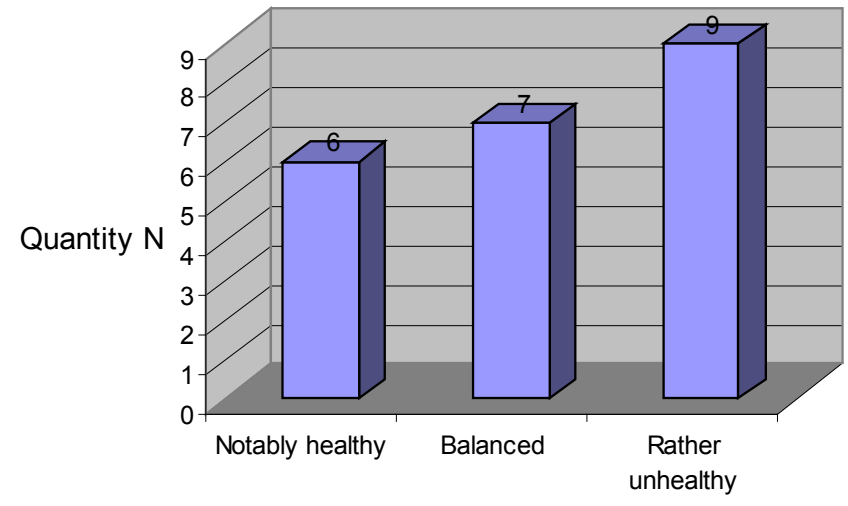

Figure 6: How would you assess your diet? 
Citation: Thonack J, Hofmann M (2012) Preventative Medicine as a Service in Tourism - Health Awareness. Primary Health Care 2:116. doi:10.4172/2167-1079.1000116

\section{Types of Exercise}

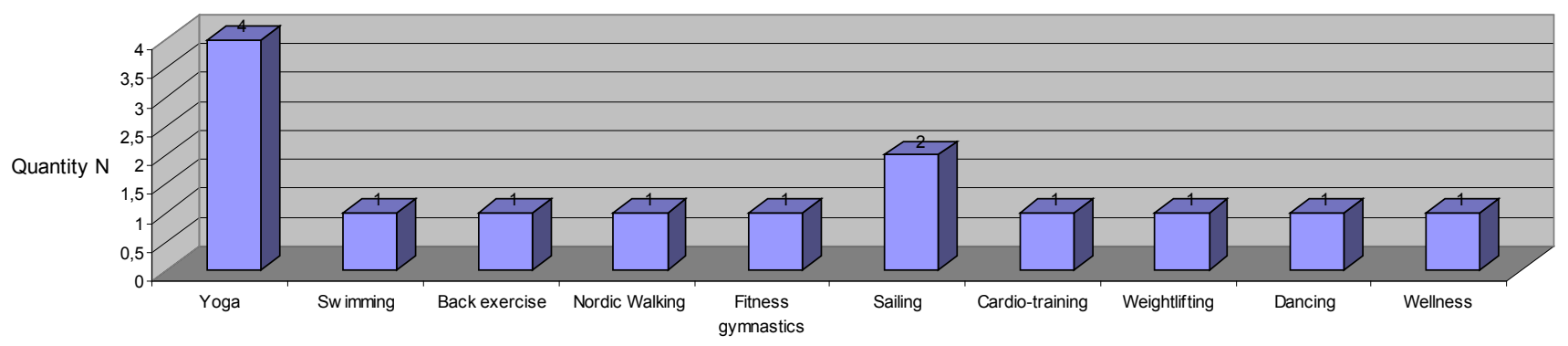

Figure 7: Which types of exercise do you do?

health awareness. Despite the guests' opinion that they have high health awareness, a lot of them do not exercise, see their workdays as stressful, and have unhealthy diets. The actual measures for healthcare that can be done on one's own lie in the areas of nutrition, exercise and stress reduction. Here the political intention for personal responsibility is of great significance. In society, the knowledge about health preservation is present.

It fails when transferred to the different areas. An open question is how specialized the knowledge of the population about the various areas is. The educational system is overwhelmed with projects for health and so-called "health weeks", however a continuously structured and goal-defined knowledge transfer about exercise, nutrition and stress reduction is not carried out. For example, in the area of exercise, one can clarify that an adjustment of the contents of exercise classes is necessary. Overweight children are left alone in the process of understanding the questions: "Why should I exercise?" "Why am I so overweight?" "Why am I not accepted in sports?" Surely, one of these or other questions will be brought up. But does a knowledge transfer take place with these children? Exercise theory cannot be found in the German school system.

The results from two polled guests were interesting in that they stated they had decided on preventative medicine measures because they had expected a different examination, such as that of a family doctor. The other guests did not associate these measures with curative measures (Figure 8). The distinction between the idea of salutogenesis and pathogenesis and the contents therein is still not completely understood in the world of medicine. How should a layman then evaluate this and know that they could receive information about health preservation in the sense of salutogenesis from doctors. Are doctors able to inform citizens sufficiently on this subject matter? In the approbation guidelines organisation [6], the cross-section area 10 "Prevention and Healthcare" was created. It is a start to impart the subject matter of prevention and healthcare specifically on future doctors.

After the stay in the hotel, the guests responded to the second questionnaire. The questions in figures 9 to 11 are more related to the evaluation of the hotel and not the preventative medicine measures because the guests were questioned about their overall impression of the stay.

Figure 10 shows that despite data gained from the initial

\section{Why have you made this decision?}

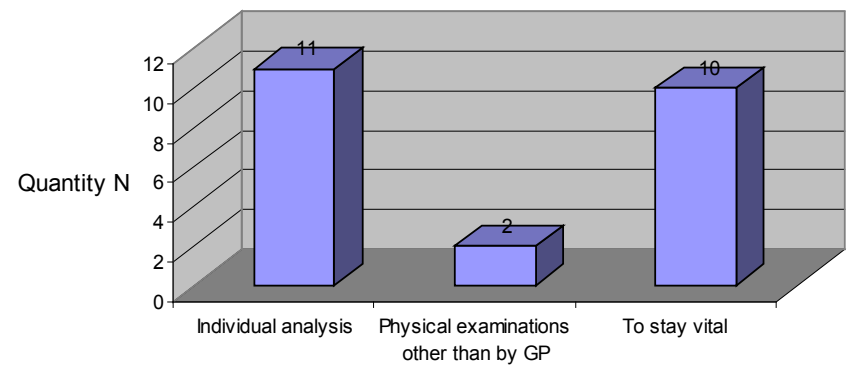

Figure 8: Why have you decided on preventative medical measures?

Were your expectations met during the stay? - Assessment (1 very good -6 very bad), Not specified -

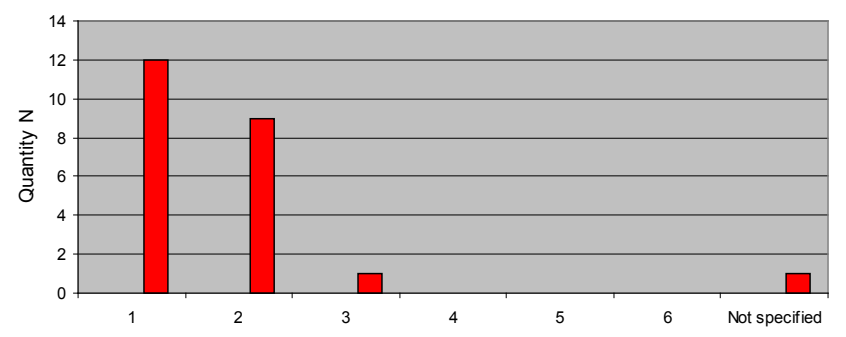

Figure 9: Were your expectations met during your stay?

questionnaire (Figure 2 and 3) a high amount of additionally gained information resulted. Because of this, one must assess the results of both questions in figures 2 and 3 carefully. Figure 1 rather correlates with figure 8.

Figure 12 clearly shows the positive resonance of preventative medicine measures. It is further shown indirectly that a change of behaviour of the guest could develop. The goal to give an introduction or additional information about prevention and healthcare for daily life to the guests was fulfilled.

Whether or not the suggestions or the interventions begun in the hotel concerning the guest's daily life have been further implemented cannot be answered. 
Citation: Thonack J, Hofmann M (2012) Preventative Medicine as a Service in Tourism - Health Awareness. Primary Health Care 2:116. doi:10.4172/2167-1079.1000116

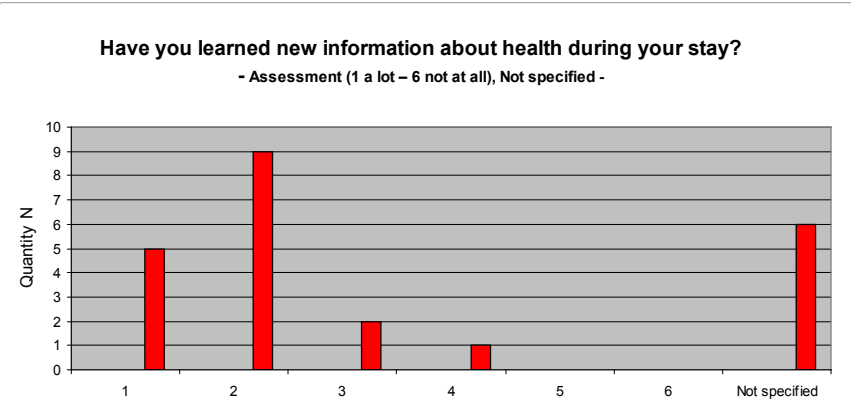

Figure 10: Have you learned new information about health during your stay?

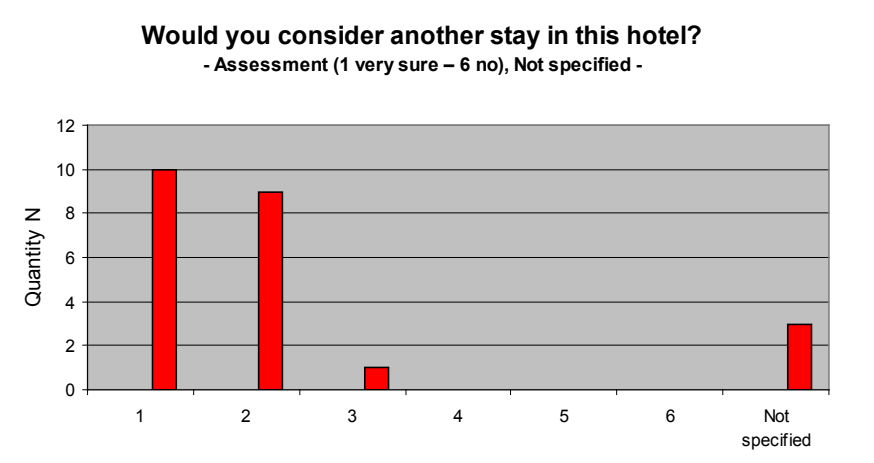

Figure 11: Would you consider another stay in this hotel?

In one year, would you undergo vitalexpertise ${ }^{\circledR}$ again? - Assessment (1 definitely -6 no), Not specified -

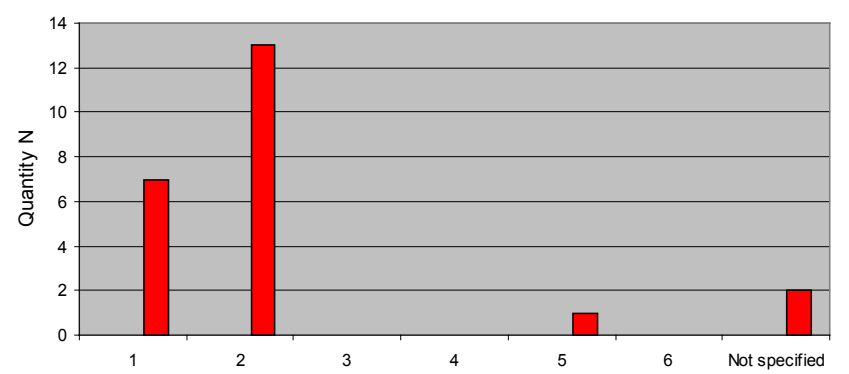

Figure 12: In one year, would you undergo vitalexpertise ${ }^{\circledR}$ again?

As long as healthcare itself deals with the prevention of illnesses, German society will not practise preventative medicine. The ideological change of the meaning of prevention and healthcare should focus on the topic of health prevention and stabilisation of effectiveness. This will not be optimally achieved through preventative campaigns [7] but through structured and well-planned communication of health measures [8]. To achieve this goal there is a solution that begins very early in life: the school subject "health education". In this subject one could teach all necessary information.

\section{Acknowledgement}

This work was supported and initially funded by the 'German Federal Ministry of Education and Research' (BMBF). We would like to thank the participants in this study for their willingness to answer our questions. We are especially grateful to Mr. Gühler, owner of the hotel "Zur Post" in the city of Bansin (Island Usedom), for his support in implementing the project. We appreciate the opportunity to take advantage of the support by vitalexpertise $\AA$ and are grateful to the German Federal Ministry of Education and Research (BMBF) for the financial support.

\section{Competing Interests}

The authors declare that they have no competing interests.

\section{Author Contributions}

Jens Thonack and Martin Hoffman cooperated in both the carrying out the study and the preparation of the manuscript.

Jens Thonack predominantly assumed responsibility of the medical and preventative contents, and Martin Hofmann was responsible for the logistical implementation and partially for the specialized questions.

\section{References}

1. http://www.evaaa.de/evaaa/innoplattform/vitalitaets-expertisen_HMS_AMS html

2. Meißner-Pöthig D, Michalak U (1997) Vitalität und ärztliche Intervention Hippokrates Verlag 64-72.

3. Bender B (2007) profil: grün - Wie viel Sicherheit verträgt die Freiheit 16-18.

4. http://www.beauty24.de/theme-tp-6797022-101048-8563062.html

5. Sozialgesetzbuch V. Prävention und Selbsthilfe.

6. http://www.gesetze-im-internet.de/_appro_2002/index.html

7. Jahresbericht (1999) Jahresbericht des Institutes für Ernährungsökonomie und -soziologie; Bundesforschungsanstalt für Ernährung und Lebensmittel.

8. http://www.bmg.bund.de/cln_042/nn_1168278/DE/Praevention/praevention node.html? nnn=true 